\title{
Three applications of dams in Nepal, Malaysia, and Turkey
}

\author{
R. Morimoto \\ Toulouse Business School, CERMAS and Department of Strategy, \\ Toulouse, France
}

\begin{abstract}
This paper empirically applies cost benefit analysis to much debated hydropower projects in Malaysia, Nepal and Turkey. The study selects an interesting mixture of cases, as main characteristics of each dam, geographical locations of each dam, and the development stage of each country differ. The study brings together all the major issues attached to each hydropower project and estimates the quantitative impacts of these controversial dams. The cost benefit analysis model in this study takes into account of premature decommissioning of dams and the correlation between the parameters of generation capacity, total construction cost and construction period. The mean cumulative net present value at the $100^{\text {th }}$ year of the analysis with the 5\% discount rate for Sharada-Babai dam in Nepal shows a positive figure, whereas the mean cumulative net present value after 100 years for both Bakun dam in Malaysia and Ilisu dam in Turkey are negative. The mean value of the cumulative net present value for Sharada-Babai becomes negative when the pure rate of time preference is larger than $6 \%$; for Bakun and Ilisu, converge to zero as pure rate of time preference becomes larger. The sensitivity analysis shows the dominant positive impact of the generation capacity parameter on net present value for Bakun; and the parameter expressing initial expected increase in economic output for Sharada-Babai and Ilisu.
\end{abstract}

Keywords: Bakun, cost benefit analysis, hydro power development, Ilisu, net present value, sensitivity analysis, Sharada-Babai.

\section{Introduction}

The serious negative effects of large dams have been widely discussed, and the roles of large dams have been questioned, over the past two decades (WCD [1]). However, there are still numerous plans to build massive dams worldwide, 
especially in developing countries. Are these dams really worthwhile to build? Will they contribute to the sustainable development process? This paper tries to answer the question based on an empirical application of probabilistic CBA (cost benefit analysis) to much debated hydroelectric projects in Nepal, Malaysia and Turkey. The study selects an interesting mixture of cases, as main characteristics of each dam, geographical locations of each dam, and the development stage of each country differ. The study brings together all the major issues attached to each hydropower project and estimates the quantitative impacts of these controversial dams. The CBA model in this study is further developed from the previous version in Morimoto and Hope $[2,3])$, in order to take into account the correlation between the generation capacity, the total construction cost and the construction period.

This paper consists of the following four sections. The next section describes the characteristics of three hydropower projects. The third section explains the methodology and lists the variables used in the model. The fourth section presents the findings from the study including sensitivity analysis and the variation of cumulative Net Present Value (NPV) against the pure rate of time preference. The last section summarizes and concludes the study.

\section{Malaysia: Bakun Hydro Project}

Together with rapid economic growth, electricity consumption in Malaysia grew at $5.6 \%$ between 2000 and 2005, according to APEC Energy demand and Supply Outlook 2006. The electricity demand in Malaysia is mainly met by three major sources; gas (47\%), hydro (10\%), and coal (43\%) in 2005 , according to Tenaga National Berhad (TNB). The government intends to balance this ratio and tries to increase hydropower generation, which has led to the controversial Bakun Hydroelectric Project construction plan. The Bakun dam on Balui River in Sarawak state on Borneo Island will be South East Asia's largest dam with a generation capacity of $2.4 \mathrm{GW}$, and is supposed to cater for the rising industrial demand for electricity in Malaysia. Although this development of a remote part of Malaysia might improve the regional economy, through increased employment and infrastructure development, such as access roads and airports, there are also many costs associated with it. It will flood 70,000 hectares of rainforests and abundant timber sources, equivalent to the size of Singapore, and fertile agricultural lands. The construction costs for this gigantic project will be huge, despite the fact that there would be a possibility of insufficient demand to absorb its enormous generation of electricity. Another great concern of the project is the displacement of 10,000 indigenous people. The entire ecosystem of the area also might change; especially large negative effects on downstream fishery are anticipated. The area is already suffering from siltation due to timber extraction, which is highly likely to restrict power generation capacity in the near future. Poor working conditions at the dam site are also reported. The project has been delayed due to serious environmental, social and financial problems. The project was originally scheduled to complete in 2003, however was revised to 2007 . 


\section{Nepal: Sharada-Babai Hydro Project}

The electricity demand in Nepal is estimated to grow at 7.5\% annually until 2020 (Asian Development Bank (ADB) [4]). Lack of electricity may restrict economic growth, especially in the industrial and service sectors - the fastest growing economic sectors in Nepal (Pokharel [5]). The electrification rate in Nepal is still very low - only about one third of the population has access to electricity, and the rate is much lower for rural population (ADB [4]). The country's major sources of energy for rural population are fuelwood and kerosene (Mahapatra [6]). The government in Nepal plans to provide electricity to $55 \%$ of the population by 2007, which requires rapid expansion of electrification in the country (ADB [4]). Nepal has the great potential for hydropower and its theoretical generation capacity is $83 \mathrm{GW}$ according to the Nepal Electricity Authority (NEA). Currently, there are many planned hydropower projects in Nepal in order to utilize the resources. The proposed Sharada-Babai hydropower project in the Mid Western Region of Nepal has an installed capacity of 93MW, and requires a 5-year construction period. The project is located between the tropical and sub-tropical climatic regions of the country. The land of the reservoir area is very fertile, whose main crops are paddy and wheat. More than 300 families will be relocated from the core project area. The major impact of the project will be the submergence of rich forest and agricultural land. The impoundment and reduced flow downstream will change the hydrology of the basin, which is likely to affect the aquatic environment of the river. The holy pond and the Kali Vhagwati (a temple of religious and cultural importance) will be inundated due to the reservoir formation. Infrastructure relocation such as a school, a post office, and suspension bridges are also required.

\section{Turkey: Ilisu Hydro Project}

The electricity consumption in Turkey has been growing by the rate of $6 \%$ per year as a result of rapid urbanization and industrialization (Turkey's Energy Strategy by Ministry of Foreign Affairs [7]). The electricity demand in Turkey is met by oil (38\%), coal (27\%), gas (23\%), and hydro and renewable $(12 \%)$, according to Turkish Ministry of Foreign Affairs [7]. The Ilisu dam is presently the largest hydro project in Turkey with a generation capacity of 1,200 MW. The dam will be located on the Tigris River in South-East Anatolia, $65 \mathrm{~km}$ upstream of the Syrian and Iraqi border. The project plan was stopped in 2002 as it is extremely controversial for a variety of political, social, environmental, economic, and archeological reasons. However, the project resurfaced in 2005. The project will submerge approximately 52 villages and 15 small towns and affect between 25,000 and 78,000 people mainly ethnic Kurds. (http://www.rivernet.org/turquie/ilisu.htm) The people living in the project area are mainly farmers who grow cereals, vegetables, fruits, cotton, tobacco as well as herbs and a small number of shepherds. Although there is no real commercial fishing in the River Tigris, farmers fish for local consumption. People moving to cities will face sharp changes in their daily activities and traditional ways of life 
which often cause significant problems of adaptation to the urban environment, family tensions, psychological stress and social disruption. Hasankeyf, the main town to be inundated is the only town in Anatolia which has survived since the middle ages without destruction, and is also known as an important pilgrimage center. The town's history dates back at least 2,700 years. Being a rich treasure of Assyrian, Christian, Abassidian-Islamic and Osmanian history in Turkey, Hasankeyf was awarded complete archeological protection by the Turkish department of culture in 1978, and 22 monuments have been entered on the Turkish Cultural Inventory List in 1981. The lack of funds and time means that it will be difficult to relocate the treasures that will be inundated. Moreover, even after successful relocation, they may not create the same aesthetic impact in a new site. Hasankeyf is also a tourist destination and a holiday resort, so inundation of this town is likely to affect tourism in the area. The area to be flooded by the reservoir includes 7,353 hectares of good agricultural land, 4,820 hectares of medium-low quality land, and 15,675 hectares of land not suitable for growing crops. (http://www.rivernet.org/turquie/ilisu.htm) Since, the amount of trees and shrubs in the area to be flooded is relatively small, the carbon dioxide release from the reservoir is assumed to be small compared to the other reservoirs of the same size in dense forest (IEG [8]). Solid waste and wastewater of major cities are being dumped into the Tigris River without any treatment. The Ilisu reservoir will vastly reduce the auto-purification capacity of the Tigris. This is then highly likely to cause water quality degradation and possibly to affect the downstream fishery negatively.

\section{Methodology}

The CBA model used in this study is further developed from the previous version in Morimoto and Hope ([2] and [3]), in order to take into account the correlation between the generation capacity, the total construction cost and the construction period. Table 1 lists the variables used in the CBA model: the core variables included in all the case studies are PG (power generation), CP (clean power), EG (economic growth), CC (construction cost), OM (operation and maintenance cost), RE (resettlement cost), IN (losses due to inundation of land), AC (accident cost). The project specific variables are FI (impacts on downstream fishery) for Bakun; IF (infrastructure cost) for Sharada-Babai; and LT (tourism loss) and AS (archaeological loss) for Ilisu. A brief summary of the equations used in the model, and all the parameters in the model and their values are listed in Morimoto and Hope [9]. Dixon et al. [10] argue that the appropriate time horizon should be long enough to encompass the useful life of the proposed project, therefore the project life of 100 years is selected in this study.

Some inputs in the CBA model seem to be clearly correlated to each other. If the generation capacity were to be reduced, the total construction cost and the construction period would also be reduced accordingly. Hence, we assume that a minimum value for one of these variables implies a minimum value for the others. The same assumption is made for most likely and maximum values. The correlation coefficients that this implies for Bakun, Sharada-Babai and Ilisu 
project are all above 0.7 . There is a wide range in the data for GC (generation capacity) in the Bakun case, as the project size might be drastically reduced due to the protests. The minimum, most likely and max values are $0.5,0.7$ and $2.4 \mathrm{GW}$ respectively. Therefore the consideration of this input dependency would be particularly important for Bakun.

Table 1: $\quad$ Variables used in the CBA model.

\begin{tabular}{|c|c|}
\hline $\begin{array}{l}\text { Variable (core variables in } \\
\text { bold) }\end{array}$ & Description \\
\hline EG (economic growth) & $\begin{array}{l}\text { The forgone economic costs for electricity not served, which } \\
\text { will occur during the time when an alternative power } \\
\text { generation technology is not available. }\end{array}$ \\
\hline PG (power generation) & $\begin{array}{l}\text { Calculated by multiplying the quantity of electricity generated } \\
\text { by the price of electricity. A possible reduction in the quantity } \\
\text { of electricity generated due to sedimentation, and changes in } \\
\text { electricity prices, are also included in the equation. }\end{array}$ \\
\hline CP (clean power) & $\begin{array}{l}\text { The environmental benefit of avoiding damage from air } \\
\text { pollution when generating an equivalent amount of power by } \\
\text { thermal power. This benefit will occur during the time when an } \\
\text { alternative power generation technology is available. }\end{array}$ \\
\hline $\begin{array}{l}\text { IN (losses by land } \\
\text { inundation) }\end{array}$ & $\begin{array}{l}\text { Financial values of forests and agricultural lands to be } \\
\text { inundated }\end{array}$ \\
\hline AS (archaeological loss)* & $\begin{array}{l}\text { Approximated by the values of cultural antiquities being sold } \\
\text { on the market. }\end{array}$ \\
\hline CC (construction cost) & $\begin{array}{l}\text { Construction costs of the power station and transmission } \\
\text { facilities. }\end{array}$ \\
\hline FI (impacts on fishery) & Decline in revenues from fishery due to dam construction. \\
\hline LT (tourism loss) & Losses in tourism revenue as a result of the dam construction \\
\hline $\begin{array}{l}\text { OM (operation \& } \\
\text { maintenance) }\end{array}$ & O\&M costs for running the hydropower station. \\
\hline RE (resettlement cost) & $\begin{array}{l}\text { Compensation to individuals and development costs for new } \\
\text { houses and infrastructure. Theoretically, estimations of what } \\
\text { resettled people are willing to accept are preferred as better } \\
\text { estimates. However, those data are difficult to obtain and their } \\
\text { results are not very reliable, especially in developing countries. }\end{array}$ \\
\hline $\begin{array}{l}\text { IF (infrastructure relocation } \\
\text { cost) }\end{array}$ & Costs required to relocate infrastructures to be inundated \\
\hline $\mathrm{AC}$ (accident cost) & $\begin{array}{l}\text { During construction, O\&M \& special circumstances (technical } \\
\text { failure, terrorism attack or earthquake). Calculated by } \\
\text { multiplying the estimated number of deaths and injuries due to } \\
\text { the project by the economic value of deaths and injuries. } \\
\text { Assumes that accident risks are not internalized in wages. }\end{array}$ \\
\hline
\end{tabular}

*How archaeology is perceived is different from place to place and generation to generation (Carver [11]). Although there are many studies on how to place values on archaeological sites, there is no simple conclusion for this argument (Carman et al. [12]; Carver [11]; Darvil et al. [13]; Lipe [14]; Schaafsma [15]).

The data are given as ranges, collected mainly from the existing project reports including Environmental Impact Assessment (EIA) reports and energy reports. Supplementary data are based on an extensive collation of information from past studies on similar topics, newspapers, Internet and other relevant sources. The most appropriate data for each parameter are selected using my best knowledge on the energy policy of the country, their current situation and future 
direction of power generation. Best efforts are made to find as accurate and representative data as possible. Visiting the project site and interviewing government officials, energy experts, policymakers, researchers, academics, environmentalists and locals during our fieldtrip in Malaysia, Nepal and Turkey have greatly helped such decision making process. Some of these data may not be very accurate or precise. Many of the values are tentative and open to criticism. However, this is inevitable, as many variables are not readily quantifiable and some data have a limited availability because of the project complexity or simply they do not exist. Repeated runs of the model obtain a probability distribution of possible outcomes, which is a more defensible procedure than just using single values for inputs that are in reality not well known.

\section{Results}

Table 2 lists the impact of each variable on the NPV for each project; EG (economic growth), PG (power generation), and CC (construction cost) are significant in all the projects; IN (inundation loss) for Bakun and Sharada-Babai; and AS (archaeological loss) for Ilisu. The impact of CC (construction cost) is huge as much as EG (economic growth), but not as prolonged. The sharp decay of the positive impacts of EG (economic growth) and PG (power generation) can be explained as a result of serious sedimentation problems. In comparison, AS (archaeological loss) and LT (tourism loss) are long lasting negative impacts, and are also not recoverable once the dam is constructed. The sensitivity analysis shows the dominant positive impact of GC (generation capacity) on NPV for Bakun, and EO (initial expected increase in economic output) for both SharadaBabai and Ilisu.

For Bakun, the $5^{\text {th }}$ percentile, mean and the $95^{\text {th }}$ percentile of cumulative NPV with a premature decommissioning option at a $5 \%$ discount rate at $\mathrm{t}=100$ years are $\$-9.6,-2.8$, and 7.0 billion respectively (without decommissioning they are $\$$ $-9.9,-2.9$, and 7.0 billion respectively; showing that the option of premature decommissioning gives a slight improvement). The mean, the $5^{\text {th }}$ and the $95^{\text {th }}$ percentiles of the cumulative NPV are all initially strongly negative due to the large construction cost. The $95^{\text {th }}$ percentile recovers quickly after the construction is complete since the benefits of increased economic growth soon outweigh all the costs. Its peak is at $\mathrm{t}=40$ years, as after this date the revenue is insufficient to cover the total annual costs. The $5^{\text {th }}$ percentile and the mean values both remain negative throughout the life of the project. The mean shows a slight recovery from year 10 until year 30 followed by a permanent downward movement. The $5^{\text {th }}$ percentile shows a similar pattern to the mean, though it already starts declining at $\mathrm{t}=20$ years due to the large anticipated costs such as inundation and fishery losses.

For Sharada-Babai, the $5^{\text {th }}$ percentile, mean and the $95^{\text {th }}$ percentile of the NPV at the $5 \%$ discount rate at $\mathrm{t}=100$ years with premature decommissioning option are $\$-0.009,0.14$, and 0.34 billion respectively. The results without the premature decommissioning option are exactly the same since the recoverable 
costs such as $\mathrm{AC}$ (accident costs during operation and maintenance period) and OM (operation \& maintenance cost) are small for this specific project. The range of cumulative NPV over time shows that the huge initial capital costs are gradually outweighed by the anticipated large benefits from power generation and increased economic growth.

Table 2: Mean cumulative present values for the variables at $\mathrm{t}=100$ years in US\$ billion.

\begin{tabular}{lcccc}
\hline & & Bakun & Sharada-Babai & Ilisu \\
\hline PVEG & Economic growth & $\mathbf{+ 1 3}$ & $\mathbf{+ 0 . 1 8}$ & $\mathbf{+ 1 3 . 8}$ \\
PVPG & Power generation & $\mathbf{+ 3 . 6}$ & $\mathbf{+ 0 . 2 1}$ & $\mathbf{+ 3 . 3}$ \\
PVCP & Clean power & +0.9 & +0.03 & +0.5 \\
PVIN & Inundation loss & $\mathbf{- 1 0 . 5}$ & $\mathbf{- 0 . 0 9}$ & -0.2 \\
PVAS & Archaeological loss & - & - & $\mathbf{- 9 . 5}$ \\
PVCC & Construction cost & $\mathbf{- 4 . 5}$ & $\mathbf{- 0 . 1 4}$ & $\mathbf{- 4 . 9}$ \\
PVFI & Fishery loss & -4.4 & - & -0.9 \\
PVLT & Tourism loss & - & - & -3.5 \\
PVOM & O \& M cost & -0.4 & -0.03 & -0.5 \\
PVRE & Resettlement & -0.1 & -0.003 & -1.0 \\
PVIF & Infrastructure relocation & - & -0.02 & - \\
PVAC & Accident cost & -0.03 & -0.0004 & -0.04 \\
\hline
\end{tabular}

Note: Significant variables are expressed in bold letters.

For Ilisu, The $95^{\text {th }}$ percentile is positive whereas the mean and the $5^{\text {th }}$ percentile are negative. The mean, the $5^{\text {th }}$ percentile and the $95^{\text {th }}$ percentile of the cumulative NPV at the 5\% discount rate with the premature decommissioning option at $\mathrm{t}=100$ years are $\$-9.9,-3.5$, and 4 billion respectively. The benefits never outweigh the costs throughout the period for the $5^{\text {th }}$ percentile and the mean, while the $95^{\text {th }}$ percentile turns to be positive soon after the completion of construction. The $95^{\text {th }}$ percentile starts declining gradually after its peak at $t=40$ years. The NPV are all negative at the beginning because of large construction and resettlement costs. The NPV increases rapidly once electricity starts to be generated, however the mean and the $5^{\text {th }}$ percentile remain negative as a result of huge archaeological losses from the destruction of this important area in Turkey which has numerous unique archaeological sites as well as tourist and pilgrim attractions. The result also shows that the consideration of premature decommissioning would not improve the result, since those recoverable costs 
after premature decommissioning such as operation and maintenance cost, accidents costs during operation, and land inundation loss for this project are relatively small.

\section{Conclusion}

This study has examined the possible outcome of three highly controversial dam projects in Malaysia, Nepal and Turkey. Characteristics of each dam differ in terms of size, geographical locations, and the level of economics development. The result for the Bakun dam in Malaysia shows expected huge losses due to the inundation of the dense rainforest and the fertile agricultural lands, and the significant negative impacts on downstream fishery. The benefit of $2.4 \mathrm{GW}$ electricity supply and facilitated economic growth might outweigh these massive losses. However, this is unlikely to occur during any feasible planning horizon, as can be seen from the 5 th percentile and the mean of the cumulative NPV being negative even after 100 years. The result obtained for the Sharada-Babai dam in Nepal presents more positive outcome. There are large benefits from the increased economic growth due to an increased power supply as the country is presently seriously short of electricity, large revenues from electricity sales, and the benefits of clean hydropower, in exchange for a large construction cost and the unrecoverable loss of submerging fertile agricultural land as well as forest. This study confirms that the improvement of hydropower development in Nepal seems to be crucial given the careful consideration of the consequences to the community and the environment. The main finding for the Turkish Ilisu dam is the enormous impact of the loss of unique archaeological sites, some of which date back at least 2,700 years. The losses are not only the value of these cultural heritages and artefacts to be submerged, but also the significant number of tourists and pilgrims visiting the sites. Both the $5^{\text {th }}$ percentile and the mean of the cumulative NPV depict that the proposed project benefits will not outweigh the large costs of the project. This result coincides with the even that the project was postponed in 2002, due to significant social and environmental concerns.

The overall results show that large scale dams generally tend to create large social and environmental impacts. The Nepalese dam case illustrates that smaller scale dams seem to be more sustainable than gigantic scale dams. Furthermore, huge costs are involved in each project discussed above, therefore an increase in electricity prices might not be avoidable. However, this may not be the case for the Sharada-Babai Project, as the benefit is likely to outweigh the cost soon after the construction. The beauty of the model developed here is its flexibility: developers could choose from an array of variables that most closely fit the constraints and conditions of their individual case. Some of the available variables are either included or excluded in order to serve the differences in each project. These case studies with diverse individual concerns in this study has demonstrated that the generalized model can be a highly practical tool, with the great advantage of its simplicity and a capability to cater for almost any kind of hydropower project assessment under uncertainty. Moreover, the application of this type of probabilistic CBA model is not limited to assess only hydropower 
projects, but it is also possible to extend its ability to assess other engineering or infrastructure projects, such as new aircraft, water pipes or tunnels (for example Morimoto and Hope [16]).

The limitations of the model are such that some impacts could be much larger than the impacts included in the above model, though may not be quantifiable. For example, the scale of the resettlement for the Bakun dam is enormous and the resettlement impact is therefore expected to be huge, though this impact seems to be not fully reflected in our results. This suggests that current estimates of the resettlement cost might be too low, and that alternative approaches such as 'willingness to pay' or 'willingness to accept' might better estimate the true resettlement cost. Furthermore, some evaluations in the model might be oversimplified. There would be other possible impacts for each project not considered; some of these could be major. For example, increased malaria infection, health problem caused by reduced water quality, negative impacts on biodiversity in the area. Displaced people are further impoverished economically, and may suffer cultural decline, high rates of sickness, malnutrition, deaths, and great psychological stress. Some of the dam sites, such as Bakun, are a home of many unique species of fauna and flora, which may disappear due to the project's impact. The Bakun dam site is located in dense forest; therefore the $\mathrm{CO}_{2}$ release from the reservoir might not be negligible. These impacts are omitted from the current analysis due to lack of data and the difficulty of quantifications. Including every single impact is not possible, therefore the variables entered into the model are prioritized in each project assessment in this research. They could, however, be included in the future analysis, if relevant, with sufficient background information.

\section{References}

[1] WCD, Dams and Development: A new framework for decision-making, Earthscan, London and Sterling, 2000

[2] Morimoto R and Hope C, 'The CBA model for the Three Gorges Project in China', Impact Assessment and Project Appraisal Journal, 22(3), 205220, 2004

[3] Morimoto R and Hope C 'An extended CBA model of hydro projects in Sri Lanka', International journal of global energy issues: special issue on energy and renewable energy with economic development in developing countries, 21 (1/2), 47-64, 2004

[4] ADB, Technical Assistant Report for Nepal, Manila, 2004

[5] Pokharel S 'Hydropower for Energy in Nepal', Mountain research and Development, 21 (1), 2001

[6] Mahapatra R, 'Power the people', Appropriate Technology, Jan-Mar, 2001

[7] Ministry of Foreign Affairs, Energy Strategy, Ministry of Foreign Affairs Turkey, 2006

[8] Ilisu Engineering Group (IEG) Ilisu Dam and HEPP Environmental Impact Assessment Report April, 2001 
[9] Morimoto $\mathrm{R}$ and Hope $\mathrm{C}$, An empirical application of probabilistic CBA: three case studies on dams in Malaysia, Nepal and Turkey, JBS WP 19, http://www.jbs.cam.ac.uk/research/working_papers/2002/wp0219.pdf 2002

[10] Dixon, J.A. Scura, LF. Carpenter, RA. and Sherman, PB, 2nd ed, Economic Analysis of Environmental Impacts, The Asian Development Bank and the World Bank, London, 1994

[11] Carver. M, 'On archaeological value' Antiquity 70 45-56CTGPC (1995) Environmental Impact Statement for the Yangtze Three Gorges Project (A Brief Edition) Science Press, 1996

[12] Carman. J, Garnegie, GD, and Wolnizer. PW, 'Is archeological valuation an accounting matter?' Antiquity 73 143-8, 1999

[13] Dervil, T., Saunders, A., and Startin, B. 'A question of national importance: approaches to the evaluation of ancient monuments for the monuments protection programme in England' Antiquity 61 393-408, 1987

[14] Lipe, WD, 'Value and meaning in cultural resources' in Cleere. HF (1984) (ed.) Approaches to the Archaeological Heritages, Cambridge University Press 1-11, 1984

[15] Schaafsma. CF 'Significant unit proven otherwise: problems versus representative samples' in Cleere (1984), 1989

[16] Morimoto R and Hope C 'Making the case for developing a silent aircraft' Transport Policy 12(2) 165-174, 2005 